\title{
PHYSOR2020: TRANSITION TO A SCALABLE NUCLEAR FUTURE
}

\author{
Eugene Shwageraus ${ }^{1}$, Paul Norman ${ }^{2}$, Patrick Blaise ${ }^{3}$, Ian Farnan ${ }^{1}$, Marat Margulis ${ }^{1}$, Una \\ Baker $^{1}$, Paul Cosgrove ${ }^{1}$, Mark DeHart ${ }^{4}$, Joanne Boyle ${ }^{1}$, Claire Armstrong ${ }^{1}$
}

\author{
${ }^{1}$ University of Cambridge \\ Cambridge, United Kingdom \\ ${ }^{2}$ University of Birmingham \\ Birmingham, United Kingdom \\ ${ }^{3}$ CEA Cadarache \\ Saint-Paul-les-Drurance, France \\ ${ }^{4}$ Idaho National Laboratory \\ Idaho, USA
}

\section{OPENING STATEMENT}

Thirty years after the first PHYSOR was held in Marseille, France, the Universities of Cambridge and Birmingham collaborated to host PHYSOR2020 in the historic city of Cambridge to celebrate three decades of outstanding research in the field of nuclear reactor physics. Over 400 papers were accepted for publication in a diverse range of topics, with special sessions planned on the CORTEX project, nuclear fusion, global nuclear innovation, and small modular reactors.

Due to the global COVID-19 situation worsening between late February and early March 2020, official government restrictions on large gatherings of people and concern for the health of our delegates meant that PHYSOR2020 was not able to be held as planned. Despite the efforts of the organising committee and investigations into either postponing or holding a 'virtual conference', the tough decision was taken to cancel PHYSOR2020. We were very disappointed not to have the chance to welcome our international friends and colleagues to Cambridge, and we hope that everyone stays safe and well in these trying times.

We would like to extend our thanks to our industrial sponsors Rolls-Royce, TechnicAtome, EDF, CEA, AWE, and Frazer-Nash for their continued support of the PHYSOR2020 conference and the nuclear reactor physics community throughout this time of uncertainty.

Finally, we would like to thank all track chairs and paper reviewers for their crucial part in delivering the technical content of these proceedings.

Best wishes for thirty more years (and beyond!) of successful nuclear reactor physics research, PHYSOR2020 Organising Committee 